\title{
CONSTRUINDO UMA TIPOLOGIA DAS POLÍTICAS DE EDUCAÇÃO INTEGRAL EM TEMPO INTEGRAL
}

\author{
BUILDING A TYPOLOGY OF THE INTEGRAL AND FULL-TIME \\ EDUCATION POLICIES
}

\section{CONSTRUCCIÓN DE UNA TIPOLOGÍA DE POLÍTICAS DE EDUCACIÓN INTEGRAL A TIEMPO COMPLETO}

\author{
Cláudia da Mota Darós Parente* \\ Universidade Estadual Paulista, Professora do Departamento de Administração e Supervisão Escolar \\ (DASE), Campus de Marília; Líder do Grupo de Pesquisa e Avaliação de Políticas Educacionais (GAPE)
}

Resumo: Este trabalho apresenta uma tipologia das políticas de educação integral em tempo integral, sistematizando diferentes formas de classificá-las. Inicialmente são analisados alguns elementos que vêm norteando as políticas formuladas e implementadas pelos entes federativos. A experiência com o desenvolvimento de projetos de pesquisa e de extensão, por meio de pesquisas de campo, grupos de discussão, aplicação de questionários, realização de entrevistas e observações, possibilitou a sistematização de modelos de oferta de educação integral em tempo integral no Brasil. A categorização desses modelos permitiu a construção de uma tipologia das políticas de educação integral em tempo integral. Este estudo contribui para a caracterização, a sistematização e a análise das políticas públicas na área.

Palavras-chave: Tipologia. Tempo integral. Educação integral. Política educacional.

Abstract: This paper presents a typology of the integral and full-time education policies, systematizing different ways to classify them. Initially, the article analyzes some elements that have been guiding the policies formulated and implemented by federa-

\footnotetext{
*Doutora e Mestre em Educação pela Universidade Estadual de Campinas.
} 
tive entities. The experience with the development of research and extension projects, through field research, focus groups, surveys, interviews and observations, enabled the systematization of models of integral and full-time in Brazil. The categorization of these models enabled the construction of the typology of the integral and full-time education policies. This study contributes to the characterization, systematization and analysis of the public policies in the area.

Keywords: Typology. Full-time education. Integral education. Educational policy.

Resumen: En este trabajo se presenta una tipología de politicas de educación integral a tiempo completo, a través de la sistematización de diferentes maneras de clasificarlas. Inicialmente se analizan algunos elementos que han orientado las politicas formuladas y implementadas por las agencias federales. La experiencia con el desarrollo de proyectos de investigación y extensión, a través de la investigación de campo, grupos de enfoque, cuestionarios, entrevistas y observaciones permitieron a la sistematización de los modelos de educación integral a tiempo completo en Brasil. La categorización de estos modelos permite la construcción de una tipología de politicas de educación integral a tiempo completo. Este estudio contribuye a la caracterización, sistematización y análisis de las políticas públicas en el área.

Palabras clave: Tipología. Educación a tiempo completo. Educación integral. Política educativa.

\section{INTRODUÇÃO}

O presente estudo é resultado de reflexões e sistematizações propiciadas por meio do desenvolvimento de pesquisas e de projetos de extensão e que tiveram como foco a análise de políticas de educação integral em tempo integral. ${ }^{1}$ Por meio de pesquisas de campo, grupos de discussão, aplicação de questionários, realização de entrevistas e observações foram captados inúmeros elementos que evidenciaram a diversidade de modelos de oferta de educação em tempo integral, seja nas diferentes regiões e estados brasileiros, seja no interior de um mesmo município. Essa diversidade tem sido marcada por inúmeros condicionantes políticos, administrativos, financeiros, pedagógicos, sociais, culturais e legais. O fato é que as experiências de educação integral em tempo integral são criadas em contextos específicos e, portanto, estão repletas de heranças e influências na montagem de seus desenhos.

Em virtude disso, dois questionamentos foram os condutores deste estudo: quais os principais condicionantes das políticas de educação integral em tempo inte- 
gral que vêm sendo desenvolvidos nos últimos anos? Quais as principais características das políticas que vêm se consolidando?

Para responder a esses questionamentos, são descritos alguns dos elementos que vêm norteando as políticas formuladas e implementadas na área, a fim de que seja possível sistematizar seus principais condicionantes. Em seguida, são apresentadas algumas classificações que, juntas, podem consolidar uma tipologia das políticas de educação integral em tempo integral.

Faria (1980, p. 9), ao argumentar a importância das tipologias, informa que:

Elaborar tipologia, tipificar, é uma das atividades mentais que tanto pode preceder à compreensão, à análise, ao aprofundamento do exame racional e exaustivo de uma realidade, como pode levar às taxionomias adequadas ou inadequadas [...] empobrecedoras da visão dinâmica, multifacetada e não demarcada do real. Aquele que se satisfaça com tipologias e taxionomias caminha pelo superficial, enquanto que o que começa seu estudo conhecendo-as mas não o esgota nelas, pode, nessas formas classificatórias ter um início metódico e esclarecedor, com o qual melhor caminhará o aprofundamento progressivo do conhecimento da realidade enfocada.

Portanto, neste estudo, a tipologia é um exercício didático de tipificação das políticas de educação integral em tempo integral, sem a intenção de se fechar para outras possibilidades de classificação, e sim, impulsionando um processo de melhor descrição e compreensão das possíveis características que podem ser alvo de análise por parte de outros pesquisadores e estudos futuros.

\section{A CONSTRUÇÃO DE POLÍTICAS DE EDUCAÇÃO INTEGRAL EM TEMPO INTEGRAL E SEUS DETERMINANTES RECENTES}

A política pública é considerada no presente artigo como o Estado em ação. Desse modo, a formulação e a implementação de uma política de educação integral em tempo integral no âmbito dos sistemas de ensino materializa o interesse do Estado em atuar nessa área. A ação do Estado e, portanto, as políticas públicas são permeadas de determinantes ao mesmo tempo em que também podem determinar e/ou condicionar outras ações do próprio Estado. Compreende-se, assim, a multiplicidade de fatores que interferem na formulação e na implementação das políticas públicas na área da educação e a multidirecionalidade da própria política pública. Isso porque, à medida que as políticas vão sendo operacionalizadas, vão também determinando escolhas, ca- 
minhos, opções, negociações, conceitos e práticas no âmbito do Estado (HOWLETT; HAMESH; PERL, 2013; SECCHI, 2014).

Neste trabalho, são destacados alguns determinantes que têm influenciado a formulação e a implementação das políticas de educação integral em tempo integral, o que tem levado a políticas com diferentes características. Variados fatores influenciam e/ou condicionam a construção de políticas de educação integral em tempo integral: políticos, legais, financeiros, administrativos, pedagógicos, culturais, sociais, etc. Por exemplo: uma política em determinado município pode ter sido formulada sob o argumento legal da necessária ampliação das matrículas em tempo integral. $\mathrm{O}$ determinante a priori, portanto, foi legal. Em outro município, a existência de ações dispersas de ampliação da jornada escolar somada às questões legais pode ter levado o município a reflexões mais profundas sobre intencionalidades e funções da educação em tempo integral. O determinante pedagógico somou-se ao determinante legal.

Assim, são apresentados alguns condicionantes político-legais que, na última década, impulsionaram a formulação de políticas e ações na área e, mais do que isso, vêm determinando algumas características dessas ações. Busca-se, então, compreender a forma como as políticas de educação integral em tempo integral vêm sendo formuladas e implementadas e seus determinantes, para que seja possível identificar alguns modelos de educação integral em tempo integral atualmente em vigor e, a partir disso, delinear algumas tipologias de políticas na área.

Um dos elementos condicionantes das políticas de educação integral em tempo integral desenvolvidas na última década tem sido o Fundo de Manutenção e Desenvolvimento da Educação Básica e de Valorização dos Profissionais da Educação (Fundeb), criado por meio da Emenda Constitucional n. 53 (BRASIL, 2006). A Lei n. 11.494, de 20 de junho de 2007, que regulamentou o Fundo, trouxe determinantes importantes quanto ao financiamento da educação, considerando que a distribuição dos recursos do Fundo considera critérios de diferenciação no que se refere às etapas, modalidades e tipos de estabelecimentos de ensino (BRASIL, 2007b; DAVIES, 2008; MENEZES, 2012).

A Resolução n. 1, de 29 de julho de 2015, do Ministério da Educação, por meio da Comissão Intergovernamental de Financiamento para a Educação Básica de Qualidade, estabeleceu as ponderações a serem aplicadas para o ano 2016 (BRASIL, 2015). Essas ponderações mostram uma concepção de que, para cada "etapa”, modalidade e tipo de estabelecimento haverá uma diferenciação de custos, tomando-se como referência o fator de ponderação 1 (um) para os anos iniciais do ensino fundamental urbano. Assim, com base na referida Resolução, o fator de ponderação da oferta de 
tempo integral na creche pública, na pré-escola, no ensino fundamental ou no ensino médio é de 1,30 .

O Decreto n. 6.253, de 13 de novembro de 2007, que regulamentou a Lei $n$. 11.494 (Fundeb), conceitua a educação básica em tempo integral da seguinte forma: “[...] a jornada escolar com duração igual ou superior a sete horas diárias, durante todo o período letivo, compreendendo o tempo total que um mesmo aluno permanece na escola ou em atividades escolares [...]” (BRASIL, 2007a, grifo do autor).

Ressalta-se, assim, a possibilidade de considerar "matrícula em tempo integral" aquela derivada da jornada do aluno em uma escola que funciona em tempo integral ou a jornada do aluno em atividades diversas, sob a responsabilidade da escola, dentro ou fora dela, e que consolidam um tempo integral.

A Nota Técnica Conjunta n. 01/2011 (SEB/SECADI/FNDE) que apresenta os “[...] critérios de apropriação do número de matrículas da educação básica, para fins de cálculo de repasse dos recursos financeiros do Fundeb", ao fazer referência ao Decreto n. 6.253, especifica três formas de como as matrículas em tempo integral no ensino fundamental e médio são contabilizadas: a) matrículas de alunos com pelo menos um vínculo de escolarização e outro em atividades complementares na mesma rede e município, os quais, somados, na média, cheguem a pelo menos sete horas diárias, cinco dias na semana; b) matrícula de escolarização e matrícula em atividades complementares em redes distintas, que somadas, na média, cheguem a pelo menos sete horas diárias, cinco dias na semana; c) matrículas de escolarização em redes distintas, considerando-se as atividades complementares da mesma rede ou município, e que somados os vínculos, na média, cheguem a pelo menos sete horas diárias, cinco dias na semana (BRASIL, 2011).

O conceito de tempo integral presente no Decreto e na Nota Técnica vem influenciando a construção e/ou a legitimação de experiências e práticas de ampliação da jornada escolar no Brasil. Há indícios de que o conceito presente nos documentos citados tenha sido influenciado também por políticas e práticas em andamento, o que se articula à concepção multidirecional de política pública presente neste trabalho.

Antes da aprovação do Decreto n. 6.253, no dia 13 de novembro de 2007, foi instituído o Programa Mais Educação do Governo federal, por meio de uma Portaria Interministerial, no dia 24 de abril de 2007. Com base na análise do Decreto e dos pressupostos do referido Programa, há fortes elementos que levam a crer que o conceito de educação integral nele presente estava a serviço do formato do Programa, fortemente ancorado na oferta de oficinas no contraturno escolar, ou seja, nas chamadas "atividades complementares". 
O Decreto, para além do conceito tradicional de tempo integral exclusivamente na escola, possibilita a criação de alternativas que articulam o tempo na escola com o que denominou tempo "em atividades escolares". O conceito presente no Decreto abre espaço para a construção de inúmeras alternativas em termos de políticas de educação integral em tempo integral, muitas das quais se aproveitam da brecha legal para desenvolver "atividades escolares" que, juntas, congregam ações que passam a compor o tempo integral de um aluno, não necessariamente de uma escola. Mas as alternativas criadas estão sendo desenvolvidas em meio a inúmeros questionamentos, entre eles: quais os limites das chamadas "atividades escolares"? Quais atividades podem ser assim consideradas? São consideradas "atividades escolares" aquelas ofertadas dentro e/ou fora da escola? Ofertadas em espaços públicos e em espaços privados? Ofertadas apenas pelo Poder Público? Apenas no âmbito da Secretaria de Educação ou por diferentes Secretarias? Ofertadas por organizações da sociedade civil em parceria com o Poder Público? Embora não haja consenso, na prática, para efeito de matrículas em tempo integral e para comprovação nos órgãos de fiscalização, a resposta a essas perguntas depende da própria política de educação integral em tempo integral de cada ente federativo, ou seja, de suas concepções, de seus argumentos, de seu desenho, do currículo escolar, enfim, de sua proposta político-pedagógica.

Além do Fundeb, outro determinante atual na construção de políticas de educação integral em tempo integral tem sido o Programa Mais Educação. De acordo como o objetivo neste artigo, deseja-se evidenciar como o Programa Mais Educação vem atuando não apenas na indução de políticas de educação integral em tempo integral (LECLERC; MOLL, 2012), mas também no delineamento de modelos e experiências na área, em virtude de suas características e de seu desenho.

A análise dos enunciados do Programa Mais Educação possibilita visualizar seus vínculos e objetivos ora com a "educação integral”, ora com a "ampliação da jornada escolar", ora com a "educação em tempo integral", termos e conceitos que podem expressar proximidades na articulação entre formação integral e tempo integral a depender do projeto educativo a ser desenvolvido pelos entes federativos.

O Programa Mais Educação tem como objetivo “[...] fomentar a educação integral", contribuindo para a "[...] formação integral de crianças, adolescentes e jovens." (BRASIL, 2007c). Tem, portanto, a finalidade de "[...] contribuir para a melhoria da aprendizagem por meio da ampliação do tempo de permanência de crianças, adolescentes e jovens matriculados em escola pública, mediante oferta de educação básica em tempo integral.” (BRASIL, 2010). 
A ampliação da jornada em tempo integral será feita mediante a oferta de "[...] atividades de acompanhamento pedagógico, experimentação e investigação científica, cultura e artes, esporte e lazer, cultura digital, educação econômica, comunicação e uso de mídias, meio ambiente, direitos humanos [...].” (BRASIL, 2010).

Com base nos documentos do Programa, "educação básica em tempo integral” é compreendida como "[...] a jornada escolar com duração igual ou superior a sete horas diárias, durante todo o período letivo, compreendendo o tempo total em que o aluno permanece na escola ou em atividades escolares em outros espaços educacionais.” (BRASIL, 2010, grifo do autor).

A descrição dos objetivos e de alguns elementos da operacionalização do Programa evidencia as opções de construir um formato de jornada integral que não se concentra apenas na escola, mas que avança para outros espaços escolares, os quais são denominados "territórios educativos".

Ao enunciar os princípios da "educação integral” no âmbito do Programa Mais Educação, o Decreto n. 7.083/2010 destaca, entre outros, a “[...] constituição dos territórios educativos para o desenvolvimento de atividades de educação integral", a "[...] valorização das experiências históricas das escolas de tempo integral como inspiradoras da educação integral na contemporaneidade" e a "[...] formação inicial e continuada dos profissionais no campo da educação integral.” (BRASIL, 2010).

Entre os objetivos do Programa está sua intenção de “[...] formular política nacional de educação básica em tempo integral", "[...] disseminar as experiências das escolas que desenvolvem atividades de educação integral” e articular políticas e programas de diferentes áreas, integrando "[...] escola e comunidade, para o desenvolvimento do projeto político-pedagógico de educação integral.” (BRASIL, 2010).

A fundamentação teórica do Programa Mais Educação ressalta os desafios da "atenção integral" e da "educação integral", ou seja, da "educação/proteção", propondo estreita articulação entre os processos escolares e as políticas sociais, bem como revisão da noção de tempo (jornada) e de espaço (territórios), disseminando o conceito da intersetorialidade e o uso da expressão "[...] educação integral em tempo integral." (BRASIL, 2012, p. 17-18, grifo do autor).

Em virtude dos elementos descritos, há fortes indícios que apontam para o papel indutor do Programa Mais Educação nas políticas e nos modelos de educação integral em tempo integral. O Programa

[...] materializa a inclusão da Educação Integral e em tempo integral na agenda de políticas educacionais do governo brasileiro. [...] o desenho de uma estratégia indutora, de caráter nacional e comprometida com sua exequibilidade conceitual e 
sustentabilidade em seu financiamento [...] foi situado na amplitude e na perspectiva da diversidade e da riqueza sociocultural no país, bem como da riqueza em termos de diversidade de projetos educativos escolares e de suas múltiplas conexões com suas comunidades. (LECLERC; MOLL, 2012, p. 95-98).

Entre os elementos normativos que deram sustentação a essa estratégia indutora está a criação da Diretoria de Currículos e Educação Integral da Secretaria de Educação Básica do Ministério da Educação responsável pela gestão da educação integral em tempo integral.

O Programa Mais Educação foi progressivamente ampliado entre 2008 e 2013, o que, inicialmente, indicou algumas contribuições ao cumprimento da meta n. 6 do Plano Nacional de Educação, relativa à oferta da educação em tempo integral em, no mínimo, 50\% das escolas públicas e atendendo, pelo menos, $25 \%$ dos alunos da educação básica (BRASIL, 2014; PARENTE, 2014). No entanto, a partir de 2014, teve início um período de instabilidade no atendimento do Programa. No início de 2016, os cortes na área de educação revelaram um momento de queda na oferta do Programa Mais Educação, ao lado de outros programas, o que certamente mexerá com as conquistas temporárias na área.

Associado ao Fundeb e ajustado às especificidades do Programa Mais Educação, o Censo Escolar pode ser mais um dos determinantes dos modelos de educação integral em tempo integral desenvolvidos atualmente.

Apenas a partir do Censo Escolar de 2007, justamente no ano de aprovação da lei que regulamentou o Fundeb, é que se passou a captar o "aluno em tempo integral", inclusive contabilizando as "atividades complementares". Já no ano 2012, o Instituto Nacional de Estudos e Pesquisas Educacionais Anísio Teixeira (INEP) passou a captar também, de forma específica, os dados relativos ao Programa Mais Educação, ou seja, um tipo de "atividade complementar".

Analisando-se os Formulários de Censo Escolar 2016 (INSTITUTO NACIONAL DE ESTUDOS E PESQUISAS EDUCACIONAIS ANÍSIO TEIXEIRA, 2016a) e as orientações contidas no Caderno de Instruções para preenchimento do Censo Escolar do mesmo ano, no que se refere ao Formulário de Cadastro da Escola, o item 42 faz referência à "Atividade Complementar". Assim, o estabelecimento de ensino deve responder se oferece atividade complementa: "exclusivamente" ou "não exclusivamente" ou se "não oferece". As orientações contidas no Caderno de Instruções demarcam a articulação das atividades complementares com a ampliação da jornada escolar e com os programas federais, a exemplo do Programa Mais Educação. 
A realização de atividade complementar nas escolas é um importante instrumento de ampliação da jornada escolar. Para saber mais sobre os programas do governo federal que incentivam a realização de tempo integral nas escolas, acesse no hotsite do Censo Escolar o documento "Programas e políticas federais que utilizam os dados do Censo Escolar", texto "Política de Educação Integral (Mais Educação e Ensino Médio Inovador)". (INSTITUTO NACIONAL DE ESTUDOS E PESQUISAS EDUCACIONAIS ANÍSIO TEIXEIRA, 2016a, p. 31).

No que se refere ao tipo de atendimento, no Formulário Cadastro de Turma, entre outras opções, destaca-se a "Atividade Complementar". Caso exista esse tipo de atendimento, deve-se elencar o "Tipo de Atividade Complementar" por meio do preenchimento de um código. Para o preenchimento desse código, é preciso seguir as orientações contidas no Caderno de Instruções. No referido caderno constam códigos de 90 atividades. A atividade complementar é caracterizada como “[...] turma com atividade de livre escolha que complementa a escolarização e o currículo obrigatório. É oferecida em horário distinto ao da escolarização.” (BRASIL, 2016, p. 37). Ainda no Cadastro da Turma é necessário preencher o horário inicial e final da turma e os dias de funcionamento. Esse item é o que vai determinar se a turma funciona em tempo integral. No Formulário Cadastro do Aluno, cada aluno deve ser vinculado a uma turma de escolarização e, se for o caso, a uma turma de atividade complementar.

No Formulário Cadastro da Turma aparece ainda a opção "Turma Participante do Programa Mais Educação/Ensino Médio Inovador”. O esforço do INEP em captar informações específicas de um programa nacional revela intencionalidades políticas, bem como a legitimação de um modelo específico de oferta de tempo integral.

No site do INEP (INSTITUTO NACIONAL DE ESTUDOS E PESQUISAS EDUCACIONAIS ANÍSIO TEIXEIRA, 2016b), no item “perguntas frequentes", também foram encontradas informações relativas ao tempo integral. Assim,

O aluno será considerado em tempo integral, se o tempo de permanência diária na escola ou em atividades escolares totalizar, no mínimo, 7 (sete) horas diárias ou 35 horas semanais. Nesse cálculo, para o ensino fundamental e ensino médio são considerados o horário da escolarização e da atividade complementar e, para a educação infantil, considera-se apenas o período da escolarização.

As atividades complementares são conceituadas no site da seguinte forma:

São atividades de livre escolha da escola, que se enquadram como complementares ao currículo obrigatório, tais como: atividades recreativas, artesanais, artísticas, de esporte, lazer, culturais, de acompanhamento e reforço ao conteúdo escolar, aulas 
de informática, educação para a cidadania e direitos humanos, dentre outras. São oferecidas em horário distinto da escolarização. (INSTITUTO NACIONAL DE ESTUDOS E PESQUISAS EDUCACIONAIS ANÍSIO TEIXEIRA, 2016a).

O site também sistematiza as orientações sobre as duas opções existentes para lançamento das matrículas/turmas em tempo integral:

Em turma de escolarização com tempo de duração maior ou
igual a 7 horas. Essa forma de declarar deve ser utilizada quan-
do todos os alunos ficam em período integral numa mesma tur-
ma.
No Ensino Fundamental e Médio podem ser declarados os alu-
nos na Escolarização e na atividade complementar, sendo que
a soma da carga horária das turmas em que o aluno está vin-
culado seja maior ou igual a 7 horas diárias. Essa forma pode
ser declarada quando parte dos alunos de uma mesma turma de
escolarização não permanecem na escola em período integral.
(INSTITUTO NACIONAL DE ESTUDOS E PESQUISAS
EDUCACIONAIS ANÍSIO TEIXEIRA, 2016b, grifo do autor).

Assim, o Censo Escolar possibilita fazer dois tipos de lançamento das matrículas em tempo integral: "turma de escolarização em tempo integral”, ou seja, quando há uma turma cujos alunos cumprem uma jornada escolar de, no mínimo, 7 horas, e "turma de escolarização + atividade complementar = tempo integral", ou seja, a matrícula de um aluno numa turma de escolarização soma-se à sua matrícula em atividades complementares e, juntas, contabilizam, no mínimo, 7 horas.

Para além do Fundeb, do Programa Mais Educação e do Censo Escolar, elementos de destaque neste artigo, existem inúmeros outros determinantes que podem influenciar de forma mais ou menos efetiva as políticas de educação integral em tempo integral dos entes federativos. Sem a pretensão de esgotar a discussão, o próprio Plano Nacional de Educação pode se constituir em elemento condicionante das políticas no âmbito dos diferentes entes federativos. O Movimento das Cidades Educadoras também vem influenciando as concepções de educação e os modelos de oferta educativa em tempo integral em virtude de seus vínculos com a ampliação dos territórios educativos. Por fim, pode-se ainda citar, no contexto de Reforma do Estado, a ampliação das parcerias público-privadas e do terceiro setor, oferecendo novas possibilidades de configuração da educação integral em tempo integral.

Após a explicitação de alguns elementos condicionantes das políticas de educação integral em tempo integral, cabe apresentar uma proposta de tipologia das políticas atualmente em vigor. Não é objetivo deste trabalho limitar as possibilidades 
de categorização da política pública. Entende-se que as tipologias e as categorizações aqui descritas poderão auxiliar na análise das políticas públicas na área.

\section{CONSTRUINDO UMA TIPOLOGIA DAS POLÍTICAS DE EDUCAÇÃO INTEGRAL EM TEMPO INTEGRAL}

Conforme já explicitado no começo deste artigo, o exercício de construção de uma tipologia das políticas de educação integral em tempo integral deve resultar em melhor compreensão de como a ação do Estado é formulada e implementada. É um exercício didático que não deve ser visto de forma estanque. As classificações aqui delineadas são advindas do olhar sobre diferentes realidades captadas em inúmeros contextos de pesquisa e extensão. Deve-se alertar que, na tentativa de enquadramento de determinadas políticas às classificações aqui expostas, é possível que existam modelos mistos que se justapõem em diferentes classificações. O Quadro 1 sistematiza 12 critérios para análise das políticas de educação integral em tempo integral. Para cada critério foram estabelecidas duas classificações.

Quadro 1 - Tipologias de Políticas de Educação Integral em Tempo Integral (2016)

\begin{tabular}{|c|c|}
\hline Critério & Classificação \\
\hline \multirow{2}{*}{$\begin{array}{l}\text { Quanto à abran- } \\
\text { gência da política }\end{array}$} & Políticas de educação integral em tempo integral universais \\
\hline & Políticas de educação integral em tempo integral parciais \\
\hline \multirow{2}{*}{$\begin{array}{l}\text { Quanto à normati- } \\
\text { zação da política }\end{array}$} & Políticas de educação integral em tempo integral estruturadas \\
\hline & Políticas de educação integral em tempo integral semiestruturadas \\
\hline \multirow{2}{*}{$\begin{array}{l}\text { Quanto à formula- } \\
\text { ção da política }\end{array}$} & $\begin{array}{l}\text { Políticas formuladas e implementadas no mesmo âmbito administra- } \\
\text { tivo }\end{array}$ \\
\hline & $\begin{array}{l}\text { Políticas formuladas e implementadas por diferentes esferas de gover- } \\
\text { no }\end{array}$ \\
\hline \multirow{2}{*}{$\begin{array}{l}\text { Quanto à origem } \\
\text { dos recursos para } \\
\text { implementação da } \\
\text { política }\end{array}$} & $\begin{array}{l}\text { Políticas de educação integral em tempo integral implementadas com } \\
\text { recursos públicos }\end{array}$ \\
\hline & $\begin{array}{l}\text { Políticas de educação integral em tempo integral implementadas com } \\
\text { recursos públicos e privados }\end{array}$ \\
\hline \multirow{2}{*}{$\begin{array}{l}\text { Quanto à existên- } \\
\text { cia de relações } \\
\text { intersetoriais }\end{array}$} & $\begin{array}{l}\text { Políticas de educação integral em tempo integral implementadas no } \\
\text { âmbito da Secretaria de Educação }\end{array}$ \\
\hline & $\begin{array}{l}\text { Políticas de educação integral em tempo integral implementadas } \\
\text { intersetorialmente }\end{array}$ \\
\hline
\end{tabular}




\begin{tabular}{|c|c|}
\hline \multirow{2}{*}{$\begin{array}{l}\text { Quanto à } \\
\text { existência de } \\
\text { parcerias público- } \\
\text { privadas }\end{array}$} & $\begin{array}{l}\text { Políticas de educação integral em tempo integral implementadas pelo } \\
\text { Poder Público }\end{array}$ \\
\hline & $\begin{array}{l}\text { Políticas de educação integral em tempo integral implementadas por } \\
\text { meio de parcerias público-privadas }\end{array}$ \\
\hline \multirow{2}{*}{$\begin{array}{l}\text { Quanto ao argu- } \\
\text { mento da política }\end{array}$} & $\begin{array}{l}\text { Políticas de educação integral em tempo integral sustentadas por } \\
\text { argumentos pedagógicos }\end{array}$ \\
\hline & $\begin{array}{l}\text { Políticas de educação integral em tempo integral sustentadas por } \\
\text { argumentos sociais }\end{array}$ \\
\hline \multirow{2}{*}{$\begin{array}{l}\text { Quanto ao espaço } \\
\text { da ação educativa }\end{array}$} & $\begin{array}{l}\text { Políticas de educação integral em tempo integral restritas ao espaço } \\
\text { escolar }\end{array}$ \\
\hline & $\begin{array}{l}\text { Políticas de educação integral em tempo integral que desenvolvem a } \\
\text { ação educativa em espaços escolares e não escolares }\end{array}$ \\
\hline \multirow{2}{*}{$\begin{array}{l}\text { Quanto à forma- } \\
\text { ção do respon- } \\
\text { sável pela ação } \\
\text { educativa }\end{array}$} & $\begin{array}{l}\text { Políticas de educação integral em tempo integral implementadas por } \\
\text { profissionais da educação }\end{array}$ \\
\hline & $\begin{array}{l}\text { Políticas de educação integral em tempo integral implementadas por } \\
\text { diferentes profissionais }\end{array}$ \\
\hline \multirow{2}{*}{$\begin{array}{l}\text { Quanto ao vínculo } \\
\text { profissional do } \\
\text { responsável pela } \\
\text { ação educativa }\end{array}$} & $\begin{array}{l}\text { Políticas de educação integral em tempo integral implementadas por } \\
\text { profissionais concursados }\end{array}$ \\
\hline & $\begin{array}{l}\text { Políticas de educação integral em tempo integral implementadas por } \\
\text { profissionais com diferentes vínculos profissionais }\end{array}$ \\
\hline \multirow{2}{*}{$\begin{array}{l}\text { Quanto à organi- } \\
\text { zação curricular }\end{array}$} & Políticas de educação integral em tempo integral padronizadas \\
\hline & Políticas de educação integral em tempo integral não padronizadas \\
\hline \multirow{2}{*}{$\begin{array}{l}\text { Quanto à integra- } \\
\text { ção curricular }\end{array}$} & $\begin{array}{l}\text { Políticas de educação integral em tempo integral com currículo inte- } \\
\text { grado }\end{array}$ \\
\hline & $\begin{array}{l}\text { Políticas de educação integral em tempo integral com currículo no } \\
\text { formato contraturno }\end{array}$ \\
\hline
\end{tabular}

Fonte: $o$ autor.

\subsection{POLÍTICAS DE EDUCAÇÃO INTEGRAL EM TEMPO INTEGRAL QUANTO À ABRANGÊNCIA DA POLÍTICA}

As políticas de educação integral em tempo integral podem ser classificadas de duas maneiras quanto à sua abrangência: políticas que universalizam o tempo integral na educação básica e políticas que implementam o tempo integral de forma parcial. Essa classificação considera a abrangência do atendimento em tempo integral nas diferentes etapas da educação básica, nos diversos tipos de estabelecimentos de ensino e também no que se refere ao quantitativo de matrículas. 
As políticas de educação integral em tempo integral universais podem ser assim caracterizadas se atenderem todos os estabelecimentos de ensino e todos os alunos matriculados em uma determinada etapa da educação básica. É o caso, portanto, daquelas políticas que abrangem todas as escolas e alunos do ensino fundamental de sua rede.

Já as políticas de educação integral em tempo integral parciais atendem parcialmente os estabelecimentos de ensino e/ou os alunos matriculados em determinada etapa da educação básica de sua rede. Nessa categoria incluem-se as políticas de educação integral em tempo integral que beneficiam apenas parte dos estabelecimentos de ensino fundamental ou parte dos alunos.

A pesquisa empírica propiciou um reconhecimento dos dois tipos de política aqui classificadas e mostrou evidências de crescimento do segundo tipo. Verificou-se a existência de várias políticas de tempo integral apenas para parte das escolas de ensino fundamental da rede e políticas de tempo integral que atendem parte dos alunos de algumas escolas de ensino fundamental. O segundo tipo de política tem sido a opção de muitos entes federativos, considerando-se que o primeiro tipo exigiria um volume maior de investimentos na área da educação.

\subsection{POLÍTICAS DE EDUCAÇÃO INTEGRAL EM TEMPO INTEGRAL QUANTO À NORMATIZAÇÃO DA POLÍTICA}

Pode-se classificar a política de educação integral em tempo integral quanto à sua normatização, ou seja, a existência de documentos político-legais e pedagógicos que explicitem: objetivos, concepções, características, abrangência, desenho, currículo, organização do trabalho pedagógico, profissionais, gestão, operacionalização, entre outros elementos. Nesse exercício de classificação, considerando-se o conceito de política como toda a ação do Estado, compreende-se que qualquer ação a título de ampliação da jornada passou por algum processo de normatização, mais ou menos estruturado.

As políticas de educação integral em tempo integral estruturadas são assim classificadas quando possuírem um nível elevado de normatização, explicitando seus principais elementos e congregando normatização no âmbito legal e pedagógico. É aquela política que, entre outros elementos possíveis, tem status de política de Estado, está prevista em lei, faz parte de um Plano de Educação e possui um projeto articulador que anuncia os princípios e as diretrizes para a implementação da política. 
No entanto, é possível também encontrar políticas de educação integral em tempo integral semiestruturadas, ou seja, quando ainda não definem de forma completa todos os seus elementos e características. São aquelas políticas que já avançaram na organização do currículo das escolas que funcionam em tempo integral, porém ainda não há um projeto de rede que congregue toda a intencionalidade na área. Outro exemplo que pode ilustrar esse tipo de política é quando há um Plano de Educação com previsão de metas para a educação integral em tempo integral, há escolas funcionando em jornada integral, porém sem um projeto articulador. Também aqui podem ser incluídas aquelas políticas que resultam de adesão a programas e projetos formulados por outras esferas de governo. A adesão, nesse caso, atuaria como um aspecto da normatização.

O segundo tipo de política tem sido bastante comum em relação ao primeiro, com base nos dados captados pelas pesquisas empíricas. As descontinuidades políticas e a ausência de um planejamento em longo prazo condicionam ações pontuais na área, sem muita organicidade.

\subsection{POLÍTICAS DE EDUCAÇÃO INTEGRAL EM TEMPO INTEGRAL QUANTO À FORMULAÇÃO DA POLÍTICA}

As políticas de educação integral em tempo integral podem ser classificadas no que se refere aos responsáveis institucionais por sua formulação. Em relação a esse critério, existem políticas de educação integral em tempo integral formuladas e implementadas no mesmo âmbito administrativo. São aquelas políticas cujos formuladores e implementadores são da mesma esfera administrativa: municipal, estadual, distrital ou federal. É o caso de uma política formulada e implementada no âmbito do próprio município.

Existem ainda as políticas de educação integral em tempo integral formuladas e implementadas por diferentes esferas de governo. Nesse tipo de política, é possível encontrar políticas implementadas no âmbito municipal, por exemplo, por meio de adesão a programas formulados por outras esferas governamentais (estadual ou federal).

Durante a pesquisa empírica foi possível visualizar os dois tipos de política: políticas formuladas e implementadas pelo mesmo ente federativo, sem qualquer vínculo com outras esferas de governo, e políticas implementadas por um determinado ente federativo, mas formuladas por outras esferas de governo. 


\subsection{POLÍTICAS DE EDUCAÇÃO INTEGRAL EM TEMPO INTEGRAL QUANTO À ORIGEM DOS RECURSOS PARA SUA IMPLEMENTAÇÃO}

As políticas de educação integral em tempo integral podem ser classificadas quanto à origem dos recursos que são utilizados para atingir o objetivo da ampliação da jornada escolar das oportunidades educativas.

Existem as politicas de educação integral em tempo integral implementadas com recursos públicos, ou seja, políticas financiadas apenas com recursos legalmente destinados à manutenção e desenvolvimento de ensino ou outros recursos provenientes apenas da esfera pública.

Existem também as políticas de educação integral em tempo integral implementadas com recursos públicos e privados, ou seja, são financiadas com recursos provenientes da esfera pública e também recebem recursos de instituições privadas. Nessa classificação enquadram-se todas aquelas políticas de tempo integral beneficiadas por instituições privadas por meio da cessão de espaços físicos, de recursos humanos, materiais e pedagógicos.

Por meio dos dados coletados com as pesquisas empíricas foi possível visualizar a ocorrência dos dois tipos de política. O segundo tipo de política tem ocorrido de maneira muitas vezes assistemática por meio de cessão de espaços para realização de determinadas atividades, por exemplo. Também foram encontradas experiências nas quais há cessão de profissionais para o desenvolvimento de algumas atividades, bem como fornecimento de materiais esportivos e pedagógicos às escolas.

\subsection{POLÍTICAS DE EDUCAÇÃO INTEGRAL EM TEMPO INTEGRAL QUANTO À EXISTÊNCIA DE RELAÇÕES INTERSETORIAIS}

As políticas de educação integral em tempo integral podem ser classificadas em relação à existência de relações intersetoriais no âmbito da esfera de governo. Assim, pode-se classificá-las em políticas de educação integral em tempo integral implementadas no âmbito da Secretaria de Educação, caso sejam políticas desenvolvidas apenas pelo setor da educação.

Existem também as políticas de educação integral em tempo integral implementadas intersetorialmente, ou seja, quando há parcerias da Secretaria de Educação com outras Secretarias, Diretorias, Departamentos ou setores da administração 
municipal, a exemplo daqueles relacionados à cultura, ao esporte, à assistência social, à saúde, etc.

As informações coletadas por meio da pesquisa empírica mostraram a existência dos dois tipos de política. O segundo tipo vem crescendo, sendo possível encontrar políticas que oferecem atividades curriculares que consolidam parcerias entre a educação e outros setores da administração governamental.

\subsection{POLÍTICAS DE EDUCAÇÃO INTEGRAL EM TEMPO INTEGRAL QUANTO À EXISTÊNCIA DE PARCERIAS PÚBLICO-PRIVADAS}

É possível classificar as políticas de educação integral em tempo integral em relação à existência de parcerias público-privadas para sua implementação, ou seja, as políticas podem ser centradas apenas na ação do Poder Público ou podem ser implementadas por meio de parcerias público-privadas. Esse critério está estreitamente articulado àquele relacionado à origem dos recursos para implementação da política.

As políticas de educação integral em tempo integral implementadas pelo Poder Público, portanto, são aquelas cujas instituições responsáveis pela oferta da ação educativa são públicas. São aquelas políticas cuja ação educativa é implementada no âmbito das esferas governamentais, por meio de seus respectivos órgãos: Secretarias, Diretorias e unidades escolares.

Em contrapartida, existem políticas de educação integral em tempo integral implementadas por meio de parcerias público-privadas. Nesse tipo de política, além da responsabilidade das instituições públicas, são estabelecidas parcerias com instituições privadas para oferta das ações educativas que congregam a jornada escolar.

Tomando-se como referência a pesquisa empírica, esse segundo tipo de política pode ser exemplificado de diferentes formas: uso de espaços privados para a oferta das atividades educativas; profissionais vinculados a instituições privadas, cedidos ao Poder Público; e cessão de materiais para auxílio na implementação da política. 


\subsection{POLÍTICAS DE EDUCAÇÃO INTEGRAL EM TEMPO INTEGRAL QUANTO AO ARGUMENTO PARA SUA FORMULAÇÃO E IMPLEMENTAÇÃO}

É possível classificar as políticas de educação em tempo integral com base nos argumentos que as sustentam. São muitos os argumentos que podem levar à implementação desse tipo de política, entre os quais: os argumentos de natureza pedagógica e os argumentos de natureza social.

Assim, existem políticas de educação integral em tempo integral sustentadas por argumentos pedagógicos a priori, ou seja, são aquelas políticas que implementam a jornada integral visando a oferecer aos alunos uma educação de qualidade, propiciar melhores condições de aprendizado e oferecer mais e melhores oportunidades educativas aos alunos.

Também podem ser encontradas políticas de educação integral em tempo integral sustentadas por argumentos sociais a priori, ou seja, políticas cujo elemento impulsionador é de natureza social, estreitamente articulado à minimização da vulnerabilidade social, visando a possibilitar mais tempo de escola aos alunos vulneráveis social e economicamente.

As experiências captadas durante a pesquisa empírica mostram a dificuldade de separação entre os dois argumentos, embora o segundo tipo de política acabe se sobressaindo em razão de seu caráter seletivo, ou seja, políticas parciais que tendem a privilegiar alunos ou escolas localizadas em regiões socialmente mais necessitadas.

\subsection{POLÍTICAS DE EDUCAÇÃO INTEGRAL EM TEMPO INTEGRAL QUANTO AO ESPAÇO DA AÇÃO EDUCATIVA}

Pode-se classificar a política de educação integral em tempo integral no que se refere ao espaço da ação educativa, ou seja, restrita ao ambiente escolar ou abarcando outros espaços para além da escola.

Historicamente, as políticas que tinham como objetivo a ampliação da jornada escolar previam a oferta da educação integral apenas no espaço escolar. Por esse motivo, durante muitas décadas, o termo "escola de tempo integral" foi comumente utilizado nos estudos sobre a temática. Atualmente, essas políticas podem ser denominadas políticas de educação integral em tempo integral restritas ao espaço escolar. São justamente aquelas políticas nas quais o tempo em que o aluno se encontra em atividade curricular é restrito ao ambiente escolar, não sendo utilizado nenhum outro espaço complementar. 
São aquelas políticas que se restringem à sala de aula e aos demais espaços da escola: quadras, laboratórios, salas de vídeo, refeitório, auditório, etc.

Por outro lado, novos modelos de políticas estão surgindo com um novo viés: são as políticas de educação integral em tempo integral que desenvolvem a ação educativa em espaços escolares e não escolares. Assim, algumas políticas podem prever ações educativas que, além da escola, utilizam outros espaços. São as políticas que fazem uso de outros ambientes públicos ou privados, seja por ausência de infraestrutura escolar seja por questões pedagógicas. Como exemplo podem ser citadas experiências que fazem uso de outros espaços públicos da região onde está localizada a escola ou mesmo de espaços mais distantes e que se articulam ao transporte escolar: quadra poliesportiva, centro de lazer, campo de futebol, associação de moradores, espaços de organizações não governamentais, praças públicas, museus, etc.

A disseminação da ideia de que a cidade pode ser um espaço educativo ampliado certamente influenciou o segundo tipo de política aqui destacado. No entanto, as pesquisas empíricas mostraram que o crescimento das políticas que desenvolvem a ação educativa em espaços escolares e não escolares ocorreu muito mais em razão de uma necessidade, ou seja, da ausência de infraestrutura escolar.

\subsection{POLÍTICAS DE EDUCAÇÃO INTEGRAL EM TEMPO INTEGRAL QUANTO À FORMAÇÃO DO RESPONSÁVEL PELA AÇÃO EDUCATIVA}

As políticas de educação integral em tempo integral podem ser classificadas em virtude da formação do responsável pela ação educativa, ou seja, implementadas pelos chamados profissionais da educação ou por outros profissionais que, tradicionalmente, não faziam parte do processo educativo.

As políticas de educação integral em tempo integral implementadas por profissionais da educação são aquelas cujo ator da ação educativa é exclusivamente o profissional de educação básica devidamente licenciado, conforme a Lei de Diretrizes e Bases da Educação Nacional (BRASIL, 1996).

Já as políticas de educação integral em tempo integral implementadas por diferentes profissionais são aquelas que, além dos profissionais da educação devidamente licenciados, incorporam outros atores, legalmente denominados "leigos", ou seja, que não possuem formação específica para atuação na educação básica. Nessa classificação estão aquelas políticas que contratam arte-educadores, 
educadores sociais, instrutores, oficineiros, estudantes universitários ou outros agentes educativos que não se enquadram na categoria "profissionais licenciados".

A pesquisa empírica mostrou o surgimento de várias experiências que utilizam outros profissionais para além dos chamados profissionais da educação para a implementação de políticas de ampliação da jornada escolar. Muitas vezes, a utilização desses diferentes profissionais decorre de interesses pedagógicos que visam incorporar profissionais com perspectivas diferenciadas para enriquecimento do currículo. Outras vezes, a utilização de outros profissionais decorre da necessidade de redução dos custos com a implementação de políticas de ampliação da jornada escolar.

\subsection{POLÍTICAS DE EDUCAÇÃO INTEGRAL EM TEMPO INTEGRAL QUANTO AO VÍNCULO PROFISSIONAL DO RESPONSÁVEL PELA AÇÃO EDUCATIVA}

As políticas de educação integral em tempo integral podem ser classificadas em relação ao tipo de vínculo profissional do responsável pela ação educativa com a escola/rede de ensino.

Existem políticas de educação integral em tempo integral implementadas por profissionais concursados, ou seja, as diferentes atividades previstas no currículo escolar são de responsabilidade de profissionais devidamente concursados.

Podem ainda existir políticas de educação integral em tempo integral implementadas por profissionais com diferentes vínculos profissionais. Nesse tipo de política, além dos profissionais concursados, são contratados outros profissionais, geralmente por processos seletivos simples, em caráter temporário. É possível que sejam feitas contratações de profissionais licenciados ou não para assumirem função de professores, instrutores, educadores sociais ou outras funções associadas à área de educação. Também é possível encontrar políticas que, além dos profissionais concursados e dos profissionais contratados, aceitam o trabalho de voluntários.

O segundo tipo de política pode ser exemplificado por meio do Programa Mais Educação, do Ministério da Educação, considerando que propõe a atividade de voluntários. Geralmente, os voluntários são estudantes de cursos de licenciatura, arte-educadores e educadores sociais.

As políticas que se utilizam de diferentes vínculos profissionais vêm crescendo, conforme as experiências identificadas na pesquisa empírica. A descontinuidade política, a ausência de uma política de Estado e sólida na área, bem como as 
fragilidades no financiamento educacional abrem brechas para que as contratações e o voluntariado ganhem espaço em relação aos concursos públicos.

\subsection{POLÍTICAS DE EDUCAÇÃO INTEGRAL EM TEMPO INTEGRAL QUANTO À ORGANIZAÇÃO CURRICULAR}

É possível classificar as políticas de educação integral em tempo integral no que se refere ao nível de autonomia que oferecem à organização do currículo por parte de suas escolas.

Em razão disso, há políticas de educação integral em tempo integral padronizadas, ou seja, com currículos padronizados para cada etapa da educação básica, para o ensino fundamental, por exemplo, restando pouca autonomia às escolas no que se refere à organização do trabalho pedagógico. Geralmente são políticas estruturadas, ou seja, devidamente normatizadas.

Há, em contrapartida, as políticas de educação integral em tempo integral não padronizadas, ou seja, são aquelas políticas, estruturadas ou semiestruturadas, que deixaram a cargo das escolas a elaboração de seu currículo e a organização do trabalho pedagógico. Podem ser enquadradas nesse último tipo aquelas políticas que, em sua proposta pedagógica, apresentam várias opções organizativas ou rol de atividades, oficinas ou componentes curriculares para que as escolas façam suas devidas opções.

Os dois tipos de políticas foram encontrados na pesquisa empírica. O primeiro tipo traz algumas facilidades no que se refere à organização no âmbito do sistema de ensino, considerando que facilita a previsão de determinados profissionais para atuação na atividade educativa. No entanto, pode ser alvo de críticas por deixar pouca margem de participação da escola na definição de suas atividades.

\subsection{POLÍTICAS DE EDUCAÇÃO INTEGRAL EM TEMPO INTEGRAL QUANTO À INTEGRAÇÃO CURRICULAR}

É possível classificar as políticas de educação integral em tempo integral quanto à integração curricular, ou seja, considerando-se a forma como as atividades previstas no currículo estão organizadas e como os componentes curriculares se articulam.

As políticas de educação integral em tempo integral com currículo integrado são aquelas nas quais há integração entre os componentes curriculares do 
núcleo comum e a parte diversificada. Na organização curricular optou-se por uma integração entre esses diferentes tipos de atividades.

As políticas de educação integral em tempo integral com currículo no formato contraturno são aquelas políticas que, na ampliação da jornada escolar, concentraram num único turno, geralmente no período da manhã, as chamadas "disciplinas tradicionais" ou os componentes curriculares obrigatórios do núcleo comum. As atividades diversificadas ficaram concentradas no segundo turno.

No segundo tipo de política, conforme dados da pesquisa empírica, muitas vezes, o desenho foi delineado considerando-se os limites relativos à contratação de profissionais ou à ampliação da jornada do professor. A adoção do currículo no formato "contraturno" facilita a implantação da jornada ampliada, sem grandes alterações das estruturas administrativas e legais vigentes.

\section{CONSIDERAÇÕES FINAIS}

No presente trabalho teve-se como objetivo apresentar uma tipologia das políticas de educação integral em tempo integral, sistematizando algumas formas de classificá-las e categorizá-las para melhor analisá-las.

São muitos os condicionantes das políticas de educação integral em tempo integral atualmente em vigor. Neste trabalho, foram destacados três: o Fundeb, o Programa Mais Educação e o Censo Escolar. Existem muitos outros condicionantes políticos, econômicos, sociais, culturais, pedagógicos, legais, etc. O fato é que as políticas vêm sendo formuladas e implementadas e esses condicionantes vão configurando modelos, práticas e experiências de educação integral em tempo integral. Essa diversidade de modelos de políticas justifica em grande medida o exercício aqui delineado.

A tipologia das políticas de educação integral em tempo integral construída neste artigo considerou 12 critérios de análise, totalizando 24 classificações possíveis das políticas atualmente em vigor. Essas classificações surgiram por meio do olhar e da análise atenta de experiências em movimento, ou seja, do Estado em ação. No entanto, o exercício didático da classificação, ou seja, a tipologia em si, materializa um esquema de análise com contornos, opções e enquadramentos. Apesar disso, as classificações aqui delineadas, à medida que a política for sendo re(construída), poderão sofrer alterações. Teorias, análises e tipologias não são feitas no vazio, mas em determinados contextos sociais, históricos, políticos, econômicos e culturais. 
A sistematização aqui presente é, portanto, um convite à análise contínua das políticas de educação integral em tempo integral formuladas e implementadas pelos diferentes entes federativos, seja por meio da tipologia construída neste trabalho seja com o objetivo de construir novas perspectivas de análise.

\footnotetext{
Nota explicativa:

${ }^{1}$ Entre os projetos desenvolvidos estão: Educação Integral em Tempo Integral: promovendo debates e ações para fortalecimento de uma política pública; Educação Integral em Tempo Integral: modelos, experiências e práticas; Planejamento e Organização do Trabalho Pedagógico em Escolas de Tempo Integral; Programa Mais Educação: impactos e perspectivas nas escolas do campo.
}

\section{REFERÊNCIAS}

BRASIL. Decreto n. 6.253, de 13 de novembro de 2007. Dispõe sobre o Fundo de Manutenção e Desenvolvimento da Educação Básica e de Valorização dos Profissionais da Educação - Fundeb, regulamenta a Lei n. 11.494, de 20 de junho de 2007, e dá outras providências. Diário Oficial da União, Brasília, DF, 13 nov. 2007a. Disponível em: <http://www.planalto.gov.br/ccivil_03/_ato2007-2010/2007/decreto/ D6253.html>. Acesso em: 10 nov. 2015.

BRASIL. Decreto n. 7.083, de 27 de janeiro de 2010. Dispõe sobre o Programa Mais Educação. Diário Oficial da União, Brasília, DF, 27 jan. 2010. Disponível em: <http://www.planalto.gov.br/ccivil_03/_Ato2007-2010/2010/Decreto/D7083. htm>. Acesso em: 30 jun. 2016.

BRASIL. Educação integral: texto referência para o debate nacional. Brasília, DF: Mec/Secad, 2009.

BRASIL. Emenda Constitucional n. 53, de 19 de dezembro de 2006. Dá nova redação aos arts. $7^{\circ}, 23,30,206,208,211$ e 212 da Constituição Federal e ao art. 60 do Ato das Disposições Constitucionais Transitórias. Diário Oficial da União, Brasília, DF, 19 dez. 2006. Disponível em: <http://www.planalto.gov.br/ccivil_03/Constituicao/Emendas/Emc/emc53.htm>. Acesso em: 08 mar. 2016.

BRASIL. Lei n. 11.494, de 20 de junho de 2007. Regulamenta o Fundo de Manutenção e Desenvolvimento da Educação Básica e de Valorização dos Profissionais da Educação - Fundeb, de que trata o art. 60 do Ato das Disposições Constitucionais Transitórias; altera a Lei $\mathrm{n}^{\circ} 10.195$, de 14 de fevereiro de 2001; revoga dispositivos das Leis $n^{\text {os }} 9.424$, de 24 de dezembro de 1996, 10.880, de 09 de junho de 2004, e 10.845, de 05 de março de 2004; e dá outras providências. Diário Oficial da União, Brasília, DF, 20 jun. 2007b. Disponível em: <http://www.planalto.gov.br/ccivil_03/_ ato2007-2010/2007/lei/111494.htm>. Acesso em: 08 mar. 2016. 
BRASIL. Lei n. 13.005, de 25 de junho de 2014. Aprova o Plano Nacional de Educação (PNE) e dá outras providências. Diário Oficial da União, Brasília, DF, 25 jun. 2014. Disponível em: <http://www.planalto.gov.br/ccivil_03/_Ato2011-2014/2014/ Lei/L13005.htm>. Acesso em: 11 maio 2015.

BRASIL. Lei n. 9.394, 20 de dezembro de 1996. Estabelece as diretrizes e bases da educação nacional. Diário Oficial da União, Brasília, DF, 20 dez. 1996. Disponível em: <http://www.senado.gov.br/sicon/ExecutaPesquisaLegislacao.action>. Acesso em: 30 jun. 2016.

BRASIL. Ministério da Educação. Resolução n. 1, de 29 de julho de 2015. Aprova as ponderações aplicáveis entre diferentes etapas, modalidades e tipos de estabelecimento de ensino da educação básica, para vigência no exercício de 2016. Diário Oficial da União, Brasília, DF, 29 jul. 2015. Disponível em: $<$ http://www.fnde. gov.br/fnde/legislacao/resolucoes/item/6829-resolu\%C3\%A7\%C3\%A3o-mecn\%C2\%BA-1,-de-29-de-julho-de-2015>. Acesso em: 28 jun. 2016.

BRASIL. Nota Técnica Conjunta n. 01/2011 (SEB/SECADI/FNDE). Apresenta metodologia para definição do quantitativo de matrículas do Censo Escolar de 2011. Disponível em: <http://www.fnde.gov.br/index.php/fundeb-legislacao>. Acesso em: 30 jun. 2016.

BRASIL. Portaria Normativa Interministerial n. 17, de 24 de abril de 2007. Institui o Programa Mais Educação, que visa fomentar a educação integral de crianças, adolescentes e jovens, por meio do apoio a atividades sócio-educativas no contraturno escolar. Diário Oficial da União, 26 abr. 2007c. Disponível em: <http://portal.mec. gov.br/arquivos/pdf/mais_educacao.pdf>. Acesso em: 10 nov. 2015.

DAVIES, N. Fundeb: a redenção da Educação Básica? Campinas: Autores Associados, 2008 .

FARIA, L. M. S. de. Prefácio. In: BRASIL. MEC. INEP. Tipologia da Educação Extra-escolar. Brasília, DF: INEP, 1980.

HOWLETT, M.; HAMESH, M.; PERL, A. Política pública: seus ciclos e subsistemas - uma abordagem integradora. Rio de Janeiro: Elsevier, 2013.

INSTITUTO NACIONAL DE ESTUDOS E PESQUISAS EDUCACIONAIS ANÍSIO TEIXEIRA. Formulários e Cadernos de Instruções. Disponível em: $<$ http:// portal.inep.gov.br/basica-censo/formularios-e-cadernos-de-instrucoes $>$. Acesso em: 30 jun. $2016 \mathrm{a}$.

INSTITUTO NACIONAL DE ESTUDOS E PESQUISAS EDUCACIONAIS ANÍSIO TEIXEIRA. Perguntas frequentes. Disponível em: <http://portal.inep.gov.br/ web/educacenso/matricula/perguntas-frequentes $>$. Acesso em: 30 jun. 2016 b. 
LECLERC, G. de F. E.; MOLL, J. Programa Mais Educação: avanços e desafios para uma estratégia indutora da Educação Integral e em tempo integral. Educar em Revista, n. 45, p. 91-110, jul./set. 2012.

MENEZES, J. S. S. Educação em tempo integral: direito e financiamento. Educar em Revista, Curitiba, n. 45, p. 137-152, jul./set. 2012.

PARENTE, C. da M. D. Educação em Tempo Integral e Programa Mais Educação: aproximações e distanciamentos das regiões brasileiras em relação à meta prevista no projeto de lei do novo Plano Nacional de Educação (PNE). Contrapontos, Itajaí, v. 14, n. 3, p. 618-633, set./dez. 2014.

SECCHI, L. Políticas públicas: conceitos, esquemas de análise, casos práticos. São Paulo: Cengage Learning, 2014.

Recebido em: 05 de julho de 2016 Aceito em: 15 de agosto de 2016

Endereço para correspondência: Avenida Hygino Muzzi Filho, 737, 17525-000, Marília, São Paulo, Brasil; claudiadaros@marilia.unesp.br 